\title{
FENOMENA OVER EDUCATION DAN UNDER EDUCATION DALAM PASAR KERJA WANITA
}

\author{
Wiko Saputra ${ }^{1}$ dan Junaidi ${ }^{2}$ \\ ${ }^{1}$ Tanjung Biru Research Institute \\ Jalan M. Hatta No. 3 Rt. 001/Rw. 002 Kel. Anduring Kec. Kuranji Padang 25151 \\ 2 Pascasarjana Universitas Bung Hatta Padang \\ Jalan Khatib Sulaiman Padang \\ E-mail: wiko_saputra@yahoo.com
}

Diterima 1 Mei 2011 / Disetujui 9 September 2011

\begin{abstract}
The phenomenon of over education and under education is a phenomenon in which a labor force with higher education levels hold jobs that do not fit with the level of education. The opposite, someone with a lower educational level would occupy a higher job. This study uses data SUSENAS 2009 for the Province of West Sumatra. The research shows, there is the phenomenon of over education and under education in the female labor market in West Sumatra and there are significant income related to the phenomenon of over education and under education in the women of labor market. It is necessary to link and match between education and female labor market in the formal sector. The policy of labor exploitation through unfair wage system for workers needs to be done so that the phenomenon of over education and under education will have positive impact for companies and workers concerned.
\end{abstract}

Keywords: over education, under education, female labor market, formal sector

\begin{abstract}
Abstrak: Fenomena over education dan under education adalah fenomena dimana seorang tenaga kerja dengan tingkat pendidikan yang lebih tinggi menduduki pekerjaan yang tidak sesuai dengan tingkat pendidikannya. Sebaliknya, seorang dengan tingkat pendidikan yang lebih rendah justru menduduki pekerjaan yang lebih tinggi. Penelitian ini mengunakan data SUSENAS 2009 untuk Provinsi Sumatera Barat. Hasil penelitian menunjukkan, ada fenomena over education dan under education dalam pasar kerja wanita di Sumatera Barat dan terdapat pengaruh hubungan pendapatan terhadap fenomena over education dan under education dalam pasar kerja wanita di Sumatera Barat. Selain itu, perlu adanya link and match antara pendidikan dan pasar kerja wanita pada sektor formal. Kebijakan eksploitasi tenaga kerja melalui sistem pengupahan yang tidak adil bagi pekerja perlu dilakukan sehingga fenomena over education dan under education akan berdampak positif bagi perusahaan dan tenaga kerja yang bersangkutan.
\end{abstract}

Kata kunci: over education, under education, pasar kerja wanita, sektor formal

\section{PENDAHULUAN}

Fenomena pasar kerja di Indonesia mengalami transformasi dalam beberapa dekade terakhir. Transformasi pertama, terjadi pada awal tahun 1990an yang ditandai oleh perubahan komposisi pasar kerja dari sektor primer ke sektor sekunder (Feridhanusetyawan \& Gaduh 2000; Manning, 2000). Kondisi ini seiring dengan transformasi ekonomi yang terjadi di Indonesia pada dekade tersebut dari sektor pertanian menuju industri. Terjadi penurunan daya serap tenaga kerja pada sektor pertanian dan alokasinya dialihkan pada sektor industri (Hill, Resosudarmo \& Vidyatama, 2008). Transformasi kedua, terjadi pada awal tahun 2000an. Pengembangan teknologi informasi yang cepat dan perkembangan ilmu pengetahuan berdampak 
pada peningkatan sektor jasa. Sehingga transformasi pasar kerja di Indonesia juga berkembang menuju terbukanya peluang kerja yang luas dalam bidang jasa (Manning, 2000; Smeru 2003). Walaupun secara umum komposisi pasar kerja di Indonesia masih besar pada sektor pertanian tapi dengan adanya perubahan dan transformasi tersebut akan memberikan perubahan dalam perkembangan pasar kerja ke depan.

Fenomena di atas baru pada sisi permintaan sedangkan pada sisi penawaran juga mengalami perubahan yang sangat besar. Kemajuan dunia pendidikan membentuk keseimbangan baru dalam pasar kerja di Indonesia (Elfindri \& Bachtiar, 2004). Ini terlihat dari struktur pendidikan tenaga kerja di Indonesia. Dalam jangka pendek saja antara tahun 20052006 terlihat dari perubahan komposisi tenaga kerja menurut pendidikan di Indoensia. Tahun 2005, jumlah tenaga kerja dengan pendidikan Sekolah Dasar (SD) atau kecil dari sekitar 39,2 persen dari total tenaga kerja di Indonesia sedangkan pada tahun 2006 menurun menjadi 37,8 persen. Dan komposisi tenaga kerja pada level pendidikan yang lebih tinggi dari SD mengalami peningkatan terutama pada jenjang akademi (BPS, 2008). Ini memperlihatkan bahwa struktur pendidikan tenaga kerja di Indonesia mengalami peningkatan.

Peningkatan level pendidikan tenaga kerja merupakan dampak dari semakin besarnya akses pendidikan bagi masyarakat Indonesia. Tapi pertanyaan, apakah peningkatan level pendidikan tenaga kerja dalam pasar kerja telah memberikan keseimbangan dalam pasar kerja di Indonesia? Dalam kenyataan, peningkatan mutu tenaga kerja melalui pendidikan belum diikuti oleh distribusi antara jumlah pekerja menurut tingkat pendidikan tertinggi yang ditamatkan dan distribusi tingkat pendidikan yang dibutuhkan menurut jenis pekerjaan (Safuan \& Nazara, 2005).

Fenomena yang terjadi dalam pasar kerja hasil studi Safuan dan Nazara (2005) menunjukan bahwa terdapat fenomena di mana seorang tenaga kerja dengan tingkat pendidikan yang lebih tinggi menduduki pekerjaan yang tidak sesuai dengan tingkat pendidikannya (lebih rendah). Kebalikannya, seorang dengan tingkat pendidikan yang lebih rendah justru menduduki pekerjaan yang lebih tinggi dari level pendidikan yang dimilikinya. Contoh, seorang pekerja yang memiliki ijazah perguruan tinggi cuma menempati posisi moving equipment and unskilled sedangkan pekerja lain dengan pendidikan SMA mampu menempati posisi pada professional workers. Kondisi ini menunjukkan adanya mismatch dalam pasar kerja di Indonesia.

Mismatch dalam pasar kerja seperti kondisi di atas dalam beberapa literature disebutkan dengan istilah "over education" dan "under education" (Duncan \& Hoffman, 1981; Sulivan, 1978; Chon \& Khan, 1995; Rumberger, 1981; Dolton \& Vignoles, 2000; Safuan \& Nazara, 2005). Fenomena over education dan under education menunjukan sebuah fenomena ketidakseimbangan pasar kerja dari sisi permintaan dan penawaran. Dalam jangka panjang ini menjadi sebuah dilema dalam pasar kerja karena ini akan menimbulkan pengangguran terbuka, masalah pada distribusi pendapatan, peraturan ketenagakerjaan dan kebijakan pendidikan (Safuan \& Nazara, 2005). Untuk itu rancangan kebijakan yang menciptakan link and match antara kebijakan pendidikan dan pasar kerja perlu dilakukan dalam mengatasi persoalan over education dan under education.

Fenomena yang menarik sebagai pengembangan studi-studi tentang pasar kerja yang over education dan under education adalah apakah kasus ini juga terjadi pada pasar kerja wanita. Bila studi-studi terdahulu cuma menganalisis pasar kerja secara umum maka perlu juga sebuah analisis yang terjadi dalam pasar kerja wanita. Ada perbedaan dari karakteristik pasar kerja wanita dengan pria. Dimana dikotomi baik secara culture, respon dan peranan masing-masing kelompok ini sangat berbeda. Dalam kondisi rumah tangga, tetap pria memiliki peranan besar dalam pendapatan. Artinya, pasar kerja pada kelompok pria lebih kompetitif dibanding wanita. Dengan kondisi ini, apa benar terjadi over education dan under education dalam pasar kerja wanita. Di sinilah studi ini akan menganalisis fenomena over education dan under education dalam pasar kerja wanita. 
Dimana konteks analisis mengunakan data pasar kerja di Sumatera Barat.

Menurut Squire (dalam Werry, 1992) ketersedian wanita untuk bekerja disebabkan oleh banyak faktor. Faktor-faktor yang berasal dari dalam diri atau internal seperti pendidikan, status perkawinan, tempat tinggal dan lainnya. Sedangkan faktor-faktor dari luar atau eksternal seperti perubahan struktur ekonomi, distribusi geografis, sosial ekonomi dan budaya. Zein (2008) juga menemukan gejala bahwa wanita bekerja untuk mengisi waktu luang dan menambah pendapatan keluarga sehingga kontribusi dalam ekonomi rumah tangga bukan saja dominasi suami.

Ketika pilihan bekerja diambil oleh wanita, mereka akan dihadapkan dengan fenomena pasar kerja yang bisa memiliki respon positif atau sebaliknya respon negatif. Pasar kerja yang kompetitif menuntut wanita untuk lebih fleksibel dalam memilih pekerjaan. Persoalan akan terjadi adalah dimana faktor pendidikan tidak lagi menjadi penentu dalam wanita memilih pekerjaan. Selagi mereka mendapatkan penghasilan (walaupun relatif kecil) mereka tidak memilih-milih posisi dimana mereka bekerja. Inilah yang menjadikan gejala over education dalam pasar kerja wanita.

Pada sisi lain, pasar kerja wanita juga mengalami under education terutama pada bidangbidang pekerjaan tertentu dimana culture skill yang melekat pada wanita tidak dimiliki oleh tenaga kerja pria seperti sekretaris. Ada beberapa kasus dan gejala dimana posisi strategis dalam perusahaan terutama yang menyangkut sekretaris atau public relation dipegang oleh wanita walaupun secara jenjang pendidikan mereka masih rendah (bisa seangkatan SMA atau Akademi).

Jadi banyak kondisi dimana akan ada gejala-gejala atau fenomena over education dan under education dalam pasar kerja wanita. Begitu juga di Sumatera Barat persoalan ini diperkirakan terjadi. Berdasarkan permasalahan diatas maka studi ini akan melihat permasalahan dari fenomena over education dan under education dalam pasar kerja wanita di Sumatera Barat.

\section{METODE PENELITIAN}

\section{Data Susenas 2009}

Penelitian ini mengunakan data Susenas 2009 untuk wilayah sampling Sumatera Barat. Diperkirakan jumlah keseluruhan sampel dari data Susenas 2009 untuk Sumatera Barat \pm 48.000 individu. Data sampel yang digunakan adalah data tenaga kerja wanita, berarti tidak semua sampel Susenas yang digunakan dalam penelitian ini. Teknik pertama adalah mereduksi sampel individu menjadi sampel angkatan kerja (usia>15 tahun). Kedua, mereduksi kembali data angkatan kerja menjadi data tenaga kerja sektor formal dengan memfilter pertanyaan pada modul ketenagakerjaan sehingga di dapatkan sampel tenaga kerja sektor formal di Sumatera Barat. Ketiga, mereduksi sample tenaga kerja formal menjadi tenaga kerja formal wanita dengan memfilter pertanyaan pada jenis kelamin. Hasil reduksi dan filter data didapatkan jumlah sampel sebesar 1.424 orang tenaga kerja.

\section{Variabel dan Definisi Operasional}

Variabel-variabel yang digunakan dalam penelitian ini terdiri dari enam variabel. (1) Over education (OVER_EDU) adalah suatu keadaan dimana pendidikan pekerja yang bekerja di lapangan usaha/jenis pekerjaan tertentu lebih tinggi dibandingkan dengan rata-rata pendidikan yang dibutuhkan di suatu lapangan usaha atau jenis pekerjaan tertentu. (2) Under education (UNDER_EDU) adalah suatu keadaan dimana pendidikan pekerja yang bekerja di lapangan usaha/jenis pekerjaan tertentu lebih rendah dibandingkan dengan rata-rata pendidikan yang dibutuhkan di suatu lapangan usaha atau jenis pekerjaan tertentu. (3) Adequated education (ADEQ_EDU) adalah bila pendidikan pekerja yang bekerja di suatu jenis pekerjaan/sektor tertentu sudah sesuai dengan tingkat pendidikan yang dibutuhkan oleh jenis atau lapangan usaha tersebut. (4) Penghasilan (Y) adalah jumlah uang (upah) yang diterima oleh pekerja wanita dalam bentuk kompensasi terhadap pekerjaan yang dilakukannya. (5) Jam kerja (HOURS) adalah jumlah jam kerja dari keselu- 
ruhan pekerjaan setiap hari selama seminggu yang lalu oleh wanita. (6) Lama pendidikan (YS) adalah jumlah rata-rata lama pendidikan yang ditempuh oleh pekerja wanita yang dihitung berdasarkan tingkat pendidikan yang diproksikan dalam bentuk angka tahun.

\section{Metode Analisis Data}

Untuk menentukan apakah tenaga kerja wanita termasuk ke dalam kriteria over education, under education atau adequated education maka diperlukan langkah-langkah sebagai berikut. (1) Menghitung lama sekolah tenaga kerja wanita. Lama sekolah dihitung dari variabel ijazah tertinggi yang ditamatkan oleh tenaga kerja wanita. Selanjutnya dikonversikan dalam angka tahun dengan mengunakan rumus sebagai berikut:

$Y S=T K+K T D-1$

dimana YS adalah rata-rata lama sekolah dari seseorang, TK adalah tahun konversi dan KTD adalah kelas tertinggi yang diduduki.

Tabel 1. Tahun Konversi dari Pendidikan Tertinggi yang Pernah Ditamatkan

\begin{tabular}{lc}
\hline $\begin{array}{c}\text { Pendidikan Tertinggi yang } \\
\text { Ditamatkan }\end{array}$ & Tahun Konversi \\
\hline 1. Tidak pernah sekolah & 0 \\
2. Sekolah Dasar & 6 \\
3. SLTP & 9 \\
4. SLTA & 12 \\
5. Diploma I & 13 \\
6. Diploma II & 14 \\
7. Akademi/ Diploma III & 15 \\
8. Diploma IV/ Sarjana & 16 \\
9. Magister (S2) & 18 \\
10. Doktor (S3) & 21 \\
\hline
\end{tabular}

Sumber: BPS (2005)

(2) Menghitung rata-rata lama pendidikan sesuai dengan kedudukan dalam pekerjaan. Posisi dalam pekerjaan utama terdiri dari : (a) tenaga kerja profesional, (b) tenaga kerja bidang manajemen, (c) tenaga administrasi, (d) tenaga penjualan, (e) tenaga jasa, (f) buruh tani, (g) tenaga kerja bagian produksi, (h) operator transportasi, (i) tenaga kerja kasar/ unskill. Dari masing-masing posisi dalam pekerjaan ini dicari rata-rata lama pendidikan dari para pekerja wanita.

(3) Menentukan kriteria over education, under education dan adequated education. Karena minimal tingkat minimal pendidikan dari suatu jenis pendidikan tertentu tidak tersedia maka informasi adequated education (adeq_edu) dihitung berdasarkan rata-rata lama sekolah (MYS) disetiap pekerjaan ditambah/dikurangi satu standar deviasinya. Seorang pekerja digolongkan ke dalam over education (over_edu) di jenis pekerjaan tertentu apabila pekerja tersebut memiliki level pendidikan (lama sekolah) lebih tinggi dari rata-rata lama sekolah ditambah satu standar deviasi di jenis/lapangan usaha tersebut. Sebaliknya, under education (under_edu) apabila seseorang memiliki lama sekolah (YS) lebih rendah dari rata-rata lama sekolah plus satu standar deviasi.

Dengan mengunakan model ekonometrik fungsi penghasilan (earning function) fenomena over education dan under education dalam pasar kerja wanita dapat didefinisikan melalui signifikansi secara statistik dari parameter regresi dari dummy variabel over_edu dan dummy variabel under_edu (Safuan \& Nazara, 2005)

Secara intuitif, over education dalam pasar kerja terjadi apabila pendidikan berpengaruh positif pada penghasilan tetapi kelebihan produktivitas (diukur dengan dummy variabel over_edu) tidak memiliki dampak pada penghasilan. Sebaliknya, fenomen under education terjadi apabila pendidikan berpengaruh positif pada penghasilan tetapi kekurangan produktivitas (diukur dari dummy variabel under_edu) berdampak positif pada penghasilan (Safuan \& Nazara, 2005). Secara matematis model dasar fungsi penghasilan pekerja ditulis sebagai berikut:

$$
\begin{aligned}
\operatorname{LnY}= & \alpha+\beta_{1} Y S+\beta_{2} H O U R S+\beta_{3} O V E R \_E D U+ \\
& \beta_{4} U N D E R_{-} E D U+\pi
\end{aligned}
$$

dimana LnY adalah logaritma natural dari penghasilan. OVER_EDU dan UNDER_EDU merupakan variabel dummy untuk over education dan under education. YS adalah vektor yang 
menunjukan independen termasuk variabel lama sekolah. Dengan mengunakan spesifikasi model di atas, dugaan ada tidaknya over education atau under education dapat diuji secara ekonometrik sebagai berikut. (1) Over education terjadi apabila $\beta_{1}>0$ tetapi $\beta_{3}$ tidak signifikan $\left(\beta_{3}=0\right)$ atau $\beta_{3}$ signifikan bertanda negatif ( $\left.\beta_{3}<0\right), \quad \beta_{4}>0\left(\beta_{3}<\beta_{4}\right)$. (2) Under education terjadi apabila $\beta_{1}>0$ tetapi $\beta_{3}$ signifikan bertanda positif $\left(\beta_{3}>0\right), \beta_{4}>0\left(\beta_{3}=<\beta_{4}\right)$.

\section{HASIL DAN PEMBAHASAN}

Fenomena over education dan under education menggambarkan konsekuensi atau akibat terjadinya pergeseran distribusi pendidikan pekerja di pasar kerja pada pekerjaan atau lapangan usaha tertentu. Seorang pekerja bekerja sebagai tenaga tata usaha dan sejenisnya (clerical and related workers) memiliki pendidikan lebih tinggi dari tingkat pendidikan yang seharusnya di butuhkan sebagai tenaga tata usaha disebut sebagai over education, under education menunjukkan sebaliknya yaitu suatu keadaan dimana pendidikan pekerja yang bekerja di lapangan usaha/jenis pekerjaan tertentu lebih rendah dibandingkan dengan rata-rata pendidikan yang dibutuhkan di suatu lapangan usaha atau jenis pekerjaan tertentu. Bila pendidikan pekerja yang bekerja disuatu jenis pekerjaan/sektor tertentu sudah sesuai dengan tingkat pendidikan yang dibutuhkan oleh jenis atau lapangan usaha tersebut dinamakan required education atau adequate education (Safuan \& Nazara, 2005).

Di Indonesia, fenomena over education dan under education ditemui dalam pasar kerja formal. Studi Safuan dan Nazara (2005) membuktikan bahwa terdapat fenomena dimana seorang tenaga kerja dengan tingkat pendidikan yang lebih tinggi menduduki pekerjaan yang tidak sesuai dengan tingkat pendidikannya (lebih rendah). Kebalikannya, seorang dengan tingkat pendidikan yang lebih rendah justru menduduki pekerjaan yang lebih tinggi dari level pendidikan yang dimilikinya. Contoh, seorang pekerja yang memiliki ijazah perguruan tinggi cuma menempati posisi moving equipment and unskilled sedangkan pekerja lain dengan pendidikan SMA mampu menempati posisi pada profesional workers. Kondisi ini menunjukan adanya mismatch dalam pasar kerja di Indonesia. Lalu bagaimana dengan kondisi pasar kerja wanita pada sektor formal di Sumatera Barat? Apakah juga terjadi fenomena overeducaton dan under education dalam pasar kerja tersebut?

Bukti adanya over education dan under education dalam pasar kerja telah memunculkan perbedaan pandangan dikalangan peneliti, akademisi serta pengambil kebijakan dalam konsep, tolok ukur, dan interprestasi. Beberapa isu penting dari perbedaan pandangan tersebut di antaranya. Fakta adanya fenomena over education dalam pasar di Indonesia sebelumnya telah diteliti oleh Safuan dan Nazara (2005). Studi Safuan dan Nazara (2005) menunjukan bahwa terdapat fenomena dimana seorang tenaga kerja dengan tingkat pendidikan yang lebih tinggi menduduki pekerjaan yang tidak sesuai dengan tingkat pendidikannya (lebih rendah). Dan kebalikan, seorang dengan tingkat pendidikan yang lebih rendah justru menduduki pekerjaan yang lebih tinggi dari level pendidikan yang dimilikinya. Contoh, seorang pekerja yang memiliki ijazah perguruan tinggi cuma menempati posisi moving equipment and unskilled sedangkan pekerja lain dengan pendidikan SMA mampu menempati posisi pada profesional workers. Kondisi ini menunjukan adanya mismatch dalam pasar kerja di Indonesia.

Dalam studi ini juga ditemukan adanya fenomena over education dan under education dalam pasar kerja wanita pada sektor formal di Sumatera Barat. Pertama, kita coba analisis secara deskriptif fenomena over education dan under education dalam pasar kerja wanita di Sumatera Barat. Hasil analisis menunjukan terjadi over education dan under education bila di lihat dari posisi pekerjaan utama. Posisi pekerjaan utama yang terdapat gejala over education dan under education berada pada dua posisi yaitu tenaga kerja bagian penjualan dan tenaga kerja bagian produksi. Pada dua posisi hampir $100 \%$ terdapat fenomena tersebut. Posisi yang sedikit mengalami fenomena over education dan under education adalah tenaga kerja profesional, tenaga kerja bagian manajemen, tenaga kerja bagian 


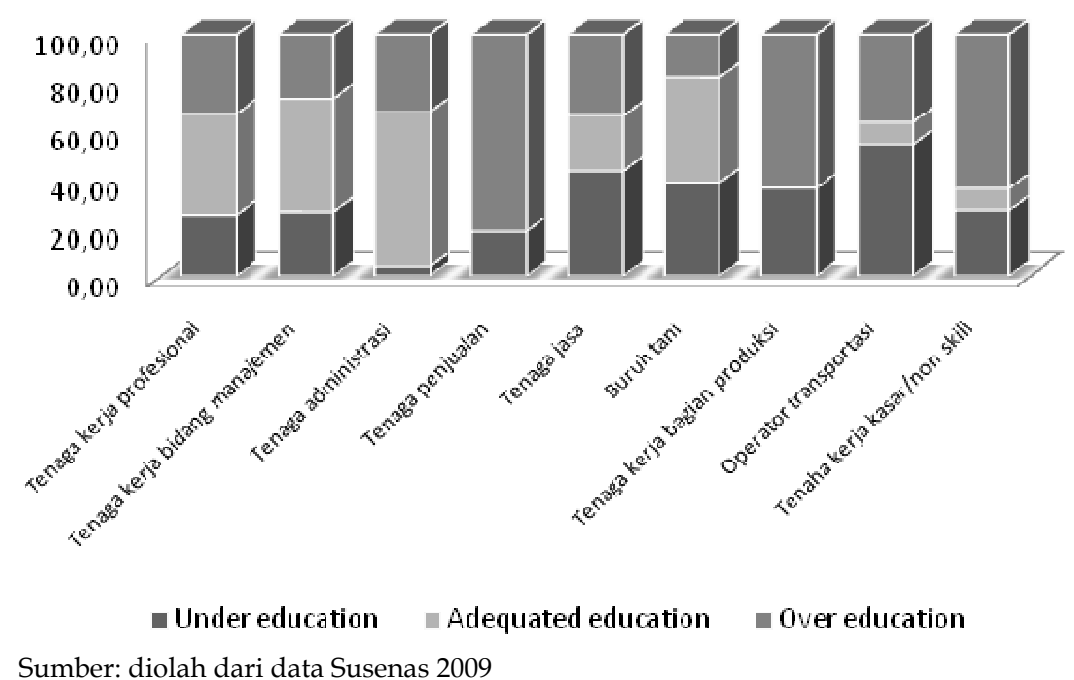

Gambar 1. Fenomena Over Education dan Under Education menurut Posisi dalam Pekerjaan Utama di Sumatera Barat, Tahun 2009

administrasi dan buruh tani. Dimana proporsi terbesar berada pada kategori adequated education. Artinya, pada empat posisi tersebut terdapat hubungan link and match antara pendidikan dan pasar kerja. patkan pekerjaan cenderung terbatas. Sehingga seorang wanita yang memiliki tingkat pendidikan yang lebih tinggi mendapatkan pekerjaan yang lebih rendah dari kualifikasi pendidikannya. over education juga disebabkan oleh faktor permintaan dalam pasar kerja. Pada sisi permintaan tenaga kerja wanita cenderung terbatas sehingga kesempatan wanita untuk menda-
Nazara, 2005). Secara intuitif, over education dalam pasar kerja terjadi apablia pendidikan berpengaruh positif pada penghasilan tetapi kelebihan produktivitas (diukur dengan dummy 
variabel over_edu) tidak memiliki dampak pada penghasilan. Sebaliknya, fenomena under pendidikan yang diperlukan dibutuhkan untuk mengisi jenis-jenis pekerjaan tertentu telah di-

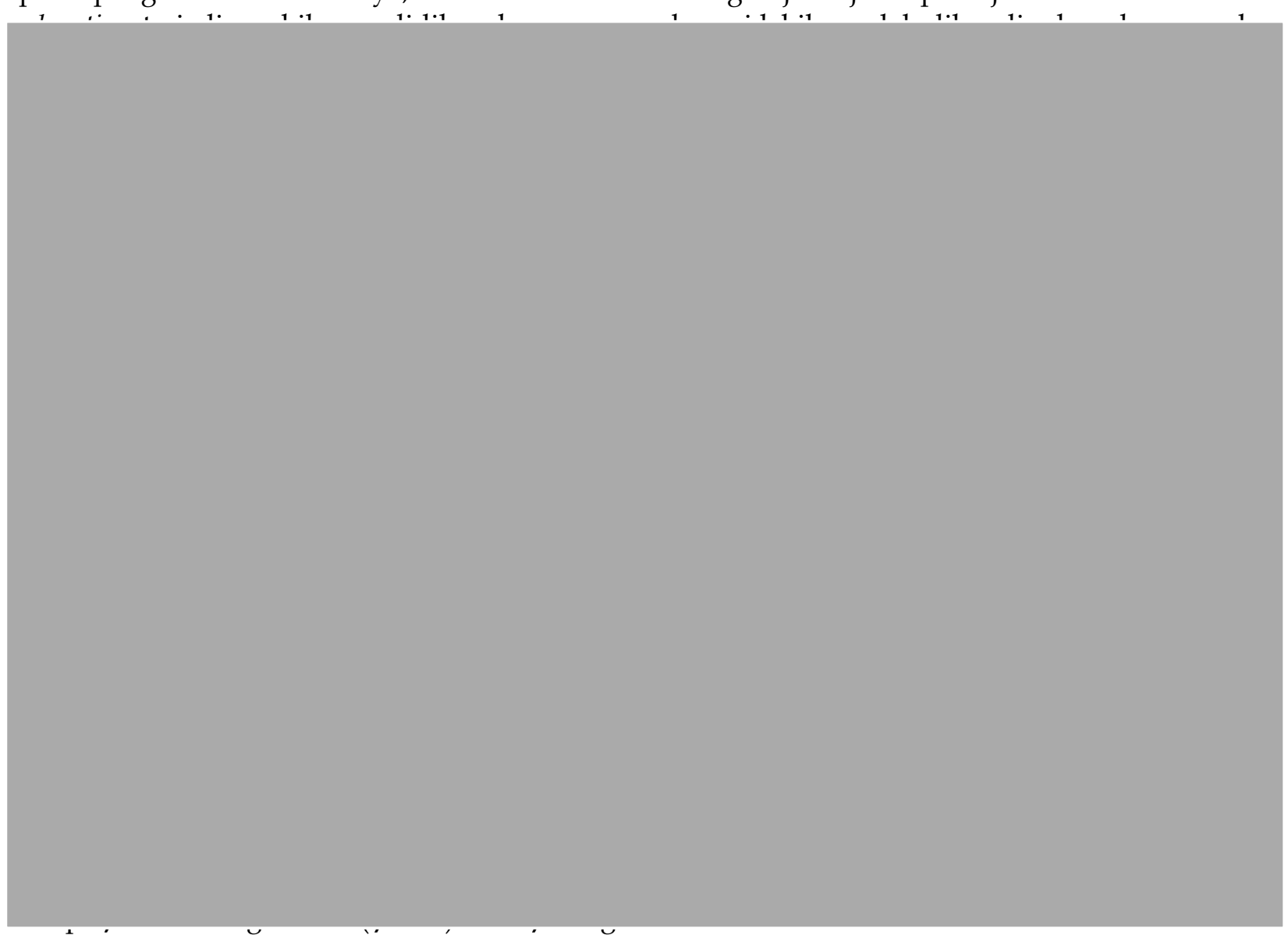

nifikan bertanda negatif $\left(\beta_{3}<0\right), \quad \beta_{4}>0\left(\beta_{3}<\right.$ $\left.\beta_{4}\right)$. Under education terjadi apabila $\beta_{1}>0$ tetapi $\beta_{3}$ signifikan bertanda positif $\left(\beta_{3}>0\right), \quad \beta_{4}>0$ $\left(\beta_{3}=<\beta_{4}\right)$

Dari hasil pengolahan data menunjukan bahwa $\beta_{1}>0$ tetapi $\beta_{3}$ signifikan bertanda negatif $\left(\beta_{3}<0\right), \beta_{4}>0\left(\beta_{3}<\beta_{4}\right)$ (lihat fungsi di atas). Dari hasil ini menunjukan bahwa terjadi fenomena over education dalam pasar kerja wanita di Sumatera Barat. Fenomena terjadinya over education ditunjukkan dari tiga aspek.

Pertama, over education diinterpretasikan sebagai penunjuk atau bukti adanya penurunan dari tingkat pengambilan secara ekonomis (economic return) di bidang pendidikan. Economic return dari pendidikan lebih tinggi menurun secara relatif terhadap pendidikan yang rendah. Di beberapa studi empiris, Rumberger (1987), Sicherman (1991), Chon and Khan (1995), Dolton and Vignoles (2000) melaporkan bahwa

\section{SIMPULAN}

Dari hasil penelitian dapat ditarik kesimpulan. Pertama, terjadi fenomena over education dan under education dalam pasar kerja wanita di Sumatera Barat. Fenomena over education dan under education mengambarkan konsekuensi atau akibat terjadinya pergeseran distribusi pendidikan pekerja di pasar kerja pada pekerjaan atau lapangan usaha tertentu. Ini membuktikan bahwa terdapat fenomena dimana seorang tenaga kerja dengan tingkat pendidikan yang lebih tinggi menduduki pekerjaan yang tidak sesuai dengan tingkat pendidikannya (lebih rendah). Kecenderungan fenomena over education dan under education ditemukan dalam karakteristik tenaga kerja baik menurut kelompok usia maupun menurut tingkat pendapatan/upah. Menurut karakteristik umur, ada kecenderungan over education terjadi pada ke- 
lompok usia muda, sedangkan kelompok usia tua cenderung cenderung memiliki karakteristik under education dan adequated education berada pada kelompok usia produktif. Kecenderungan ini sangat sesuai dengan kondisi perkembangan pendidikan saat ini yang mengarah pada perbaikan akses dan kualitas pendidikan dan kondisi pasar kerja formal. Menurut upah, ada tekanan pengunaan tenaga kerja wanita yang bersifat over education dan under education oleh perusahaan dengan memberikan upah yang lebih rendah.

Kedua, dari hasil uji regresi terhadap pengaruh hubungan pendapatan/upah terhadap fenomena over education dan under education menunjukan bahwa terjadi fenomena over education dalam pasar kerja wanita di Sumatera Barat. Fenomena terjadinya over education ditunjukkan dari tiga aspek. (1) Over education diinterprestasikan sebagai penunjuk atau bukti adanya penurunan dari tingkat pengambilan secara ekonomis (economic return) di bidang pendidikan. Economic return dari pendidikan lebih tinggi menurun secara relatif terhadap pendidikan yang rendah. (2) Over education diasosiasikan dengan terjadinya credintial education yaitu penilaian lebih dari masyarakat terhadap suatu jenis pendidikan yang tidak terkait dengan peningkatan keahlian yang dibutuhkan oleh suatu lapangan atau jenis pekerjaan tertentu. (3) Over education merupakan salah satu indikator adanya occupational mismatch atau adanya pekerja yang tidak memperoleh pekerjaan yang dapat memaksimalkan tingkat pendidikan dan kemampuan yang dimilikinya. Bahkan dalam arti yang lebih luas adanya occupational mismatch dapat diartikan sebagai petunjuk adanya sumberdaya manusia yang tidak termanfaatkan (underutilization) dalam perekonomian.

Diperlukan kebijakan untuk mengatasi fenomena ini. Pertama, perlu adanya link and match antara pendidikan dan pasar kerja wanita pada sektor formal. Kedua, kebijakan pendidikan merupakan entry point, dimana perlu sebuah kebijakan pendidikan bagi wanita yang diarahkan sesuai dengan permintaan dari pasar kerja wanita seperti peningkatan akses dan kualitas pada pendidikan kejuruan (SMK) dan diploma yang sesuai dengan culture skill dari wa- nita seperti bidang administrasi, bidang operator produksi dalam industri menengah yang memerlukan ketelitian dan ketekunan. Ketiga, perlu kebijakan standarisasi pendidikan, posisi kerja dan upah. Dimana kebijakan eksploitasi tenaga kerja melalui sistem pengupahan yang tidak adil bagi pekerja perlu dilakukan sehingga fenomena over education dan under education akan berdampak positif bagi perusahaan dan tenaga kerja yang bersangkutan.

\section{DAFTAR PUSTAKA}

Alisjahbana, Armida and Chris Manning. 2006. Labour Market Dimensions of Poverty in Indonesia. Bulletin of Indonesian Economic Studies, 42(2), pp. 235-261.

Becker, G.S. 1964. Human Capital. New York: National Beurau of Economic Research (NBER).

Boserup, E. 1970. Women's Role in Economic Development. New York: St. Martin's Press, Inc.

Chon, E. and Khan. S.P. 1995. The Wages Effect of Overshcooling Revisited. Labour Economics 2.

Cloog, C. 1979. Measuring Underemployment: Demographic Indicator for the United States. New York: Academic Press.

Dolton, P. and Vinogles. 2000. The Incidence and Effect of Education in the U.K. Graduate Labor Market. Economics of Education Review.

Duncan and Hoffman, S. 1981. The Incidence and Wage Effect of Over Education. Economics of Education Review.

Elfindri dan Nasri Bachtiar. 2004. Ekonomi Ketenagakerjaan. Padang: Andalas University Press.

Feridhanusetyawan, Tubagus, and Arya B. Gaduh. 2000. Indonesia's Labor Market During the Crisis: Empirical Evidence from the Sakernas, 1997-1999. The Indonesian Quarterly, 28(3). 
Hill, Hall, Budy P. Resosudarmo, and Yogi Vidyattama. 2008. Indonesia's Changing Economic Geography. Bulletin of Indonesian Economic Studies, 44(3), pp. 407-435.

Islam, Iyanatul. 2000. Employment, Labour Markets and Economic Recovery in Indonesia: Issues and Option. UNSFIR Working Paper.

Manning, Chris 2000. Labour Market Adjustment to Indonesia's Economic Crisis: Context, Trends and Implications. Bulletin of Indonesian Economic Studies, 36(1), pp. 105136.

Manning, Chris and Kurnya Roesad. 2007. The Manpower Law of 2003 and its Implementing Regulations: Genesis, Key Articles and Potential Impact. Bulletin of Indonesian Economic Studies, 43(1), pp. 58-86.

Rumberger, R.W. 1981. The Raising Incidance of Over Education in the US Labor Market. The Economics of Education Review.

Safuan dan Suahasil Nazara. 2005. Fenomena Over Education dalam Pasar Kerja di Indonesia. Jurnal Ekonomi dan Pembangunan Indonesia Vol. 1 No. 2 Tahun 2005.
Smeru. 2005. The Measurement and Trends of Unemployment in Indonesia:The Issue of Discouraged Workers. Smeru Working Paper.

Smeru. 2007. Reducing Unemployment in Indonesia: Results from a Growth-Employment Elasticity Model. Smeru Working Paper.

Soebagiyo, Daryono. 2005. Analisis Pengaruh Kesempatan Kerja, Tingkat Beban/Tanggungan, dan Pendidikan Tinggi terhadap Pengangguran di Provinsi Dati I Jawa Tengah. Jurnal Ekonomi Pembangunan FE UMS. Vol. 6, No. 1, Juni 2005, 1 - 11. Surakarta: BPPE UMS.

Sulivan, T.M. 1978. Marginal Worker, the Underutilization of America Worker. Austin: University of Texas Press

Taifur, Werry Darta. 1992. Perkembangan dan Karakteristik Angkatan Kerja Wanita di Sumatera Barat. Laporan Penelitian Lembaga Penelitian Universitas Andalas.

Zein, Alfian. 2008. Peranan Wanita Nelayan dalam Membantu Perekonomian Keluarga di Sumatera Barat. Jurnal IPTEK Terapan Vol. 2 No. 2 Tahun 2008. 